\title{
Comparative Study between Scrotal and Inguinal Approach for Repair of Communicating Hydrocele in Children
}

Abduo A. Arnous, Ibrahim M. ElSayaad, Ahmed M. Kamel*

Department of General and Pediatric Surgery, Faculty of Medicine, Al-Azhar University (Damietta), Egypt.

*Corresponding Author: Ahmed Magdi Kamel, Mobile: (+20)01023366778, E-mail: dr.a.magdi1990@gmail.com

\begin{abstract}
Background: The inguinal method is utilized for treating hydrocele in the pediatric populace. While, investigations on scrotal orchiopexy have declared herniation or hydrocele repairing via the same scrotal cut as a portion of an orchiopexy operation, there are a few researches investigating the treatments of separated communication hydrocele via a scrotal incision.

Objective: To compare between scrotal and inguinal surgery for repair of communicating hydrocele in kids with assessment of surgical period, intraoperative complications, hospitalization, and postoperative complication.

Patients and methods: This work was an interventional research accomplished in Department of Surgery, Al-Azhar University Hospital, New Damietta. 40 cases of ages from 1 year to 18 years were scheduled for communicating hydrocele repair; they were randomized into 2 groups: Group-A (scrotal approach) that included 20-cases and group-B (inguinal approach), which included 20-cases. This study was performed on systematic random sampling from April 2020 until October 2020.

Results: A highly significant change was found among studied groups regarding surgical period. In addition, a highly significant change was found between the two groups regarding postoperative hospitalization. There was significant change between both groups as regards overall satisfaction, while there was insignificant difference between groups as regards early post-operative complications.

Conclusion: The scrotal method for treating the children communicating hydrocele can be another procedure in qualified centers. The key benefits of this method were cosmesis and reduced surgical period. Nevertheless, the commonest early complication was temporal scrotal edema. This procedure delivers a simple method to the anatomical structure included in scrotal and groin pathologic characteristics with no disruptions of the inguinal duct integrity.

Keywords: Scrotal approach, Post-operative, Hydrocele, Inguinal.
\end{abstract}

\section{INTRODUCTION}

The inguinal method for treating children's inguinoscrotal pathologies is the suggested typical surgery. This operative method comprises release of the spermatic cord from the connected tissues, tissues separation, and high ligation of the patent processes vaginalis (PPV). It is significant to avoid vas and vessels injury at highly ligation of the PPV. Then, the testicle was immobile to the scrotum with no tensions (1).

Inguinal explorations with subsequent scrotal incisions are also the gold standard for treating palpable un-descended testes, but the single scrotal cut technique has gained popularity among pediatric surgeons in the last 20 years ${ }^{(2)}$.

Two major anxieties with the scrotal method are that PPV cannot be sufficiently ligated and proximal attachment cannot be detached. Lately, scrotal incisions orchiopexy has effectively been achieved on definite un-descended testis both with and without PPV (3). Furthermore, the scrotal method was utilized to modify other pathologies of PPV like inguinal herniation and hydrocele ${ }^{(1)}$.

The aim of the present study was to compare between scrotal and inguinal surgery for repair of communicating hydrocele in kids with assessment of surgical period, intraoperative complications, hospitalization, and postoperative complications.

\section{PATIENTS AND METHODS}

This work was an interventional research achieved in Department of Surgery, Al-Azhar University Hospital, New Damietta. 40 cases of ages from 1 year to 18 years were scheduled for communicating hydrocele repair. This study was performed on Systematic random sampling from April 2020 till October 2020. They were randomized into 2 groups: Group-A (scrotal approach) that included 20-cases and group-B (inguinal approach), which included 20-cases.

Inclusion criteria: Failures of the hydrocele to spontaneous resolution after one year of follow up, inability to obviously inspect testis, pain or discomfort and cosmesis.

Exclusion criteria: Patients younger than 1 year, small atrophic testes or solitary testes and connotation of hydroceles with revealing pathologies (e.g. torsions or tumors).

\section{Methods:}

1. Clinical assessment: Complete history taking including age, sex, residency, time of onset and complications.

2. Clinical examination: Vital signs to roll out haemodynamic stability of blood pressure, pulse, temperature and respiratory rate. Associated injuries: head, chest, abdomen, pelvis, neck, back and limbs. 
Routine blood tests, preoperative fitness for surgery and general anesthesia and inguinoscrotal ultrasonography.

\section{Surgical Procedures:}

\section{Scrotal incision hydrocelectomy:}

Afterwards general anesthesia induction, a crosswise skin cut was made laterally high in scrotal skin folds. The skin, dartos front, and thin cremasteric front have been cut as normal.

The testis was approached using blunt and sharp dissection of sub-cutaneous tissue. The scrotal wound was withdrown rising to ease dissection, and the cord cover and adhesion tissues were divided at the most cephalad location feasible to guarantee adequate cord extent and to probably permit entering into the lower half of the inguinal duct from below. The gubernacular links were freed to allow identifications of the testes (in the cremasteric fiber), the PPV, and the cord constructions.

The fiber and herniation sac have been sensibly detached from the cord, and the cranial sac was militarized underneath tractions into the duct and ligated with suture, like in old-style inguinal incisions hydrocelectomies. The testis was subsequently relocated into the dartos pouch, and 2 (medially and laterally) obsession sutures have been located amid the testicular tunic albuginea and internal scrotal barrier to avoid testicular ascents. Hypodermic tissues were sewed via Vicryl $3 / 0$ and the skin was sewed subcuticular with $4 / 0$ poly-propylene, with no drain insertions.

\section{Inguinal incisions hydrocelectomy:}

The $1^{\text {st }}$ stage of inguinal incisions hydrocelectomy was formation of a skin-crease inguinal cut over the exterior inguinal circle. Dissection continued downward to the outside circle and the exterior oblique aponeurosis. The exterior circle was unlocked by aponeurosis split. The ilioinguinal nerves located underneath the aponeurosis was conserved to lessen the risk of post-operative emotionlessness and pains. The spermous cord has been militarized and dislocated crosswise and upwards.

The cord and testis were softly detached via the inguinal incisions and then divided to a degree allowing mobilizations. Afterward reinsertion of the testis through the cut location, the hydrocele sac was unlocked and irrigations were done to prevent wounds contaminations by hydrocele fluids. Afterwards testing the testis and other assemblies for tumours and other lesions, PPV high-ligation has been achieved and the testis was re-positioned in the hemiscrotum. The inguinal cut was locked; the exterior oblique aponeurosis and hypodermic tissues layers have been sewed with Vicryl 3/0, and the skin was locked with sub-cuticular 4/0 polypropylene seams and no drainage pipe was located.

\section{Post-operative evaluation:}

All cases were followed up for 6-mths postoperatively. Data were collected as regards surgical period, intraoperative bleeding \& transfusion, postoperative hospitalization, early post-operative complications as seroma, hematoma and wound dehiscence and late complications as incidence of recurrence.
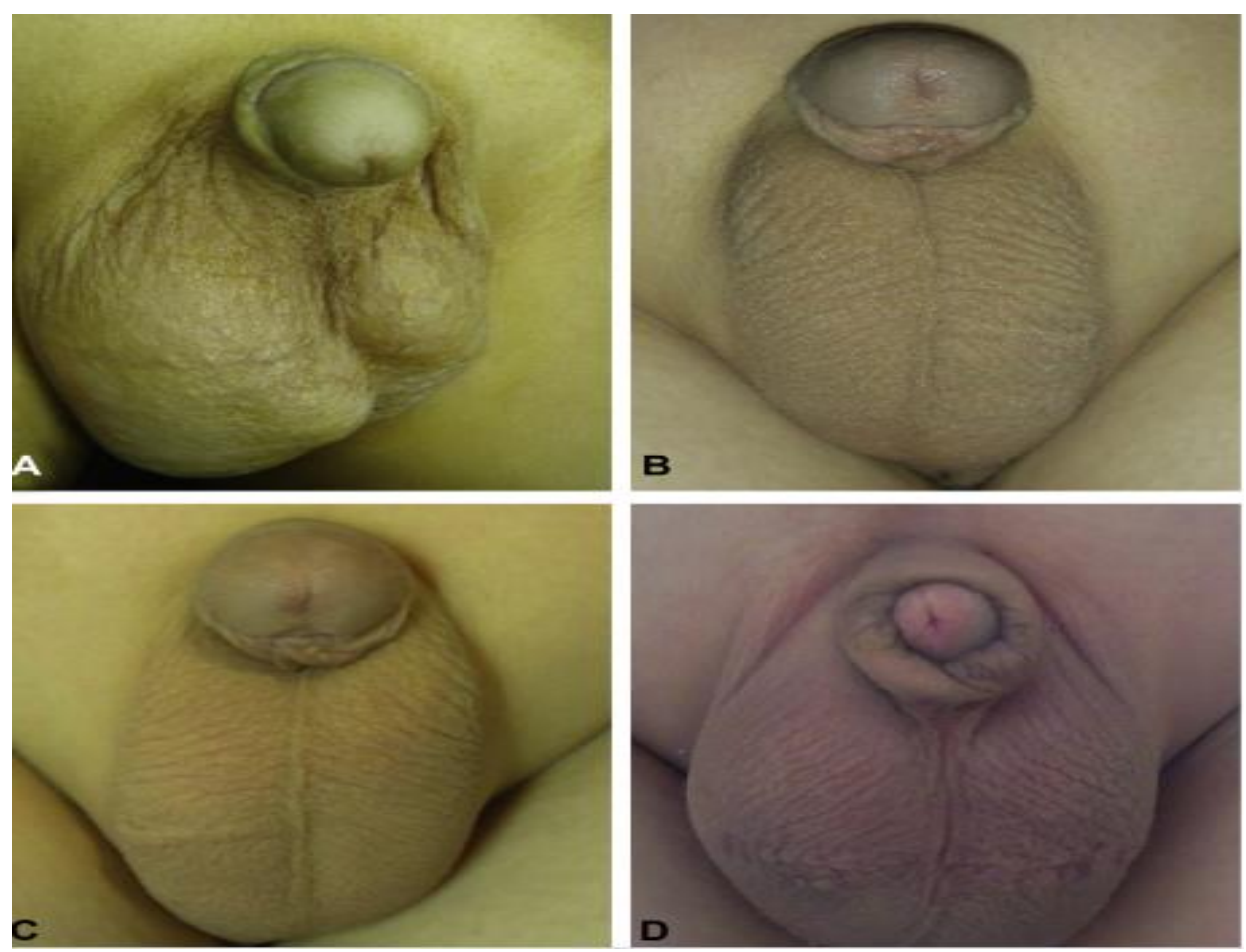

Figure (1): Pre- and post-operative look. (A) Pre-operative look of the right-hydrocele. (B and C) One-sided left and right side scrotal incisions scars, 6-mths afterward operation. (D) Two-sided scrotal incisions scars, 6-mths after operation 
Ethical approval:

The author presented him-self to contributors' parents comprised in this work and requested them to contribute thereafter explaining the aim of the work. All chosen participants' parents had full information concerning the goal and the predictable advantage of the work and written consents were obtained from them. Permission from the Faculty of Medicine, Al-Azhar University Ethical Committee was also attained and approval from Institutional Review Board was taken. This work was carried out in accordance with The Code of Ethics of the World Medical Association (Declaration of Helsinki) for studies involving humans.

\section{Statistical analysis}

The collected data were coded, processed and analyzed using the SPSS (Statistical Package for Social
Sciences) version 22 for Windows ${ }^{\circledR}$ (IBM SPSS Inc, Chicago, IL, USA). Data were tested for normal distribution using the Shapiro Walk test. Qualitative data were represented as frequencies and relative percentages. Chi square test $\left(\chi^{2}\right)$ was used to calculate difference between two or more groups of qualitative variables. Quantitative data were expressed as mean \pm SD (Standard deviation). The Kolmogorov-Smirnov testing has been utilized to confirm the normality of distributions. Independent samples t-test was used to compare between two independent groups of normally distributed variables (parametric data). $\mathrm{P}$ value $\leq 0.05$ was considered significant.

\section{RESULTS}

A nonsignificant change was found among the study groups regarding residence and age (years) (Table 1).

Table (1): Comparison among the study groups regarding demographic data

\begin{tabular}{|c|c|c|c|c|c|c|}
\hline \multirow{2}{*}{ Demographic data } & \multicolumn{2}{|c|}{$\begin{array}{c}\text { Group A } \\
(\mathbf{n}=\mathbf{2 0})\end{array}$} & \multicolumn{2}{|c|}{$\begin{array}{c}\text { Group B } \\
(\mathbf{n}=\mathbf{2 0})\end{array}$} & \multirow[t]{2}{*}{ Test of Sig. } & \multirow{2}{*}{$\mathbf{p}$} \\
\hline & No. & $\%$ & No. & $\%$ & & \\
\hline $\begin{array}{l}\text { Residence } \\
\text { Rural } \\
\text { Urban }\end{array}$ & $\begin{array}{c}14 \\
6\end{array}$ & $\begin{array}{l}70.0 \\
30.0\end{array}$ & $\begin{array}{c}12 \\
8\end{array}$ & $\begin{array}{l}60.0 \\
40.0\end{array}$ & $\begin{array}{c}\chi^{2}= \\
0.440\end{array}$ & 0.507 \\
\hline $\begin{array}{l}\text { Age (years) } \\
\text { Min. - Max. } \\
\text { Mean } \pm \text { SD. } \\
\text { Median (IQR) }\end{array}$ & \multicolumn{2}{|c|}{$2.00-17.0$} & \multicolumn{2}{|c|}{$2.0-17.0$} & $\mathrm{U}=199.50$ & 0.989 \\
\hline
\end{tabular}

$\chi^{2}$ : Chi square testing $\quad \mathbf{U}$ : Mann Whitney testing $\mathrm{p}$ : $\mathrm{p}$-value for comparison among the study groups

Group A: Scrotal approach Group B: Inguinal approach

Non-significant change was found among the study groups regarding duration of hydrocele presence (months), side and past history of hydrocele (Table 2).

Table (2): Comparison among the study groups regarding history data

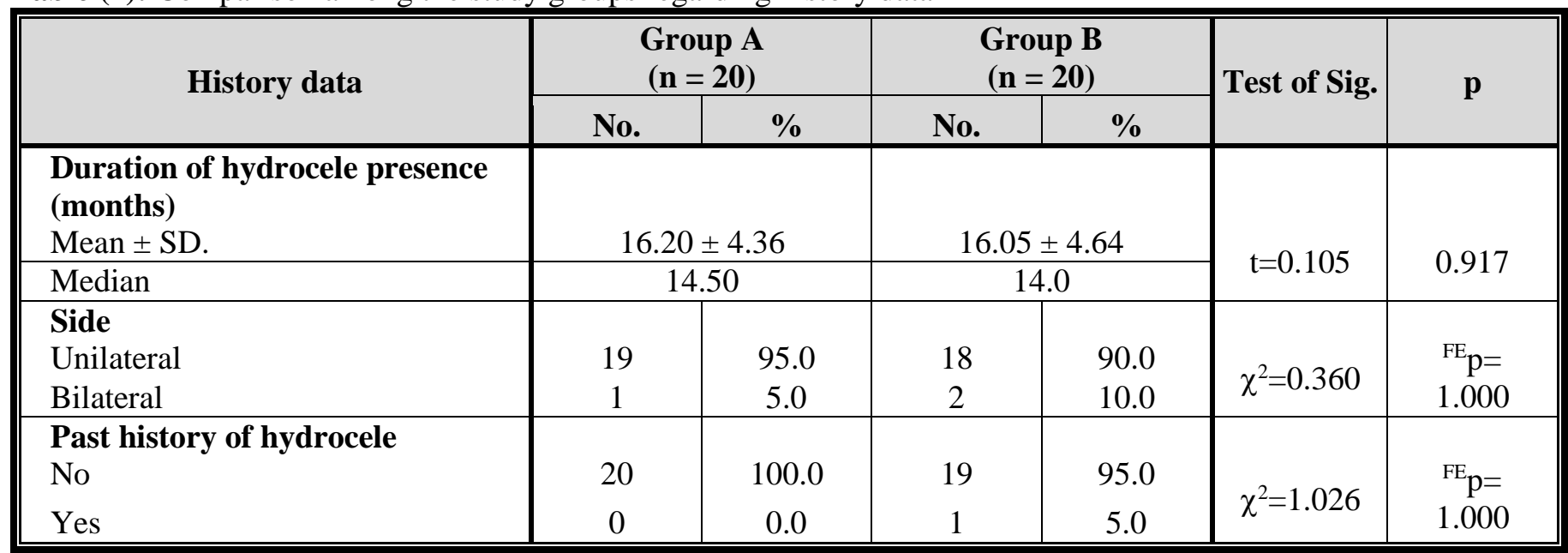

$\chi^{2}$ : Chi square testing $\quad$ FE: Fisher Exact t: Student t-testing

p: p-value for comparison among the study groups

A highly significant change was found between both groups concerning surgical period being lesser in group 1 (Table $3)$. 
Table (3): Comparison among the study groups regarding operation outcome

\begin{tabular}{|c|c|c|c|c|c|c|}
\hline \multirow[t]{2}{*}{ Operation outcome } & \multicolumn{2}{|c|}{$\begin{array}{c}\begin{array}{c}\text { Group A } \\
(\mathbf{n}=\mathbf{2 0})\end{array} \\
\end{array}$} & \multicolumn{2}{|c|}{$\begin{array}{c}\text { Group B } \\
(\mathbf{n}=\mathbf{2 0})\end{array}$} & \multirow[t]{2}{*}{ Test of Sig. } & \multirow[t]{2}{*}{$\mathbf{p}$} \\
\hline & No. & $\%$ & No. & $\%$ & & \\
\hline $\begin{array}{l}\text { Surgical period (minutes) } \\
\text { Mean } \pm \text { SD. }\end{array}$ & \multicolumn{2}{|c|}{$26.70 \pm 5.01$} & \multicolumn{2}{|c|}{$52.95 \pm 9.01$} & \multirow{2}{*}{$\mathrm{t}=11.388^{*}$} & \multirow{2}{*}{$<0.001^{*}$} \\
\hline Median & \multicolumn{2}{|c|}{26.0} & \multicolumn{2}{|c|}{56.50} & & \\
\hline
\end{tabular}

$\chi^{2}$ : Chi square testing $\mathrm{t}$ : Student t-testing

$*$ : significance at $\mathrm{p}$-value $\leq 0.05$

$\mathrm{p}$ : $\mathrm{p}$ value for comparison among the study groups

A highly statistically significant change was found between the two groups as regards post-operative hospitalization; a significant change was found between both groups as regards overall satisfaction while there was insignificant change between both groups regarding early postoperative complications (Table 4).

Table (4): Comparing among the study groups regarding final outcome

\begin{tabular}{|c|c|c|c|c|c|c|}
\hline Final outcome & \multicolumn{2}{|c|}{$\begin{array}{c}\text { Group A } \\
(\mathbf{n}=\mathbf{2 0})\end{array}$} & \multicolumn{2}{|c|}{$\begin{array}{c}\text { Group B } \\
(\mathbf{n}=\mathbf{2 0})\end{array}$} & $\begin{array}{l}\text { Test of } \\
\text { Sig. }\end{array}$ & $\mathbf{p}$ \\
\hline $\begin{array}{l}\text { Post-operative hospitalization (days) } \\
\text { Mean } \pm \text { SD. }\end{array}$ & \multicolumn{2}{|c|}{$1.05 \pm 0.22$} & \multicolumn{2}{|c|}{$2.70 \pm 0.73$} & $\mathrm{U}=$ & $<0001^{*}$ \\
\hline Median & \multicolumn{2}{|c|}{1.0} & \multicolumn{2}{|c|}{3.0} & $4.500^{*}$ & $<0.001$ \\
\hline Early post-operative complication & No. & $\%$ & No. & $\%$ & & \\
\hline Non & 14 & 70.0 & 16 & 80.0 & & \\
\hline Vascular injury & 1 & 5.0 & 2 & 10.0 & $\chi^{2}=$ & ${ }^{\mathrm{MC}} \mathrm{p}=$ \\
\hline Scrotal edema & 4 & 20.0 & 1 & 5.0 & 2.438 & 0.669 \\
\hline Orchitis/epididymitis & 1 & 5.0 & 1 & 5.0 & & \\
\hline $\begin{array}{l}\text { Late complication@6 months } \\
\text { Non }\end{array}$ & 20 & 100.0 & 20 & 100.0 & - & - \\
\hline $\begin{array}{l}\text { Overall satisfaction } \\
\text { Very good } \\
\text { Excellent }\end{array}$ & $\begin{array}{c}1 \\
19\end{array}$ & $\begin{array}{c}5.0 \\
95.0\end{array}$ & $\begin{array}{c}9 \\
11\end{array}$ & $\begin{array}{l}45.0 \\
55.0\end{array}$ & $\begin{array}{c}\chi^{2}= \\
8.533^{*}\end{array}$ & $0.003^{*}$ \\
\hline
\end{tabular}

$\chi^{2}$ : Chi square testing MC: Monte Carlo

U: Mann Whitney testing p: p-value for comparison among the study groups

*: significance at p-value $\leq 0.05$

\section{DISCUSSION}

An inborn hydrocele, cautilized via communications among the tunica and peritonea space using a PPV, frequently progresses impulsively within the first year of child life ${ }^{(4)}$. The typical method for treating is inguinal that includes release of the spermatic cord from connected tissues, tissues separation, and high ligation of the PPV. Lately, better rates of success with minimum complications have been informed when hydrocelectomy has been done by using a scrotal method ${ }^{(5)}$.

Additional researches as well established that the scrotal method is a substitute for correcting the inguinoscrotal pathologies. The benefits of this method comprise minimum post-operative scarring, as the cut is smaller, a shorter surgical period, and exclusion of any risk of ilioinguinal nerves damage as the spermatic cord is not divided. While, the post-operative risk of permanent hydrocele or herniation when PPV higher ligation is insufficient still of anxiety. Testicular ascent can as well advance post-operatively when the proximal attachment is not sufficiently detached ${ }^{(3)}$. This study aimed to make a comparison among scrotal and inguinal operation for repairing communicating hydrocele in kids.

In this study, we found that there was nonsignificant change between both groups regarding residence and age (years). This is matching with Alp et al. ${ }^{(2)}$ who revealed that there was nonsignificant change between both groups regarding cases ages. These cases' ages ranged between $1 \& 8$-yrs $(3.6 \pm 2.0$-yrs $)$ in the inguinal-group and from 1 - to 10 -yrs $(4.6 \pm 2.8$-yrs $)$ in the scrotal-group. The findings of Oh et al. ${ }^{(6)}$ are in agreement with our results as they mentioned that cases ages didn't vary among groups ( $p$-value $=0.130$ ). Analogous findings were concluded by Agnihotri $\boldsymbol{e t}$ al. ${ }^{(7)}$ who revealed that the cases ages in the inguinal-group ranged between 23 and 65 -yrs $(42.80 \pm 9.73)$, while the cases comprised in the scrotal-group had ages ranged from 22 to 65 -yrs $(41.30 \pm 11.21)$. The change in ages mean between both groups was nonsignificant.

In the present study we found that there was insignificant change between the two studied groups regarding period of hydrocele presence (months), discomfort, side and past history of hydrocele. This is in accordance with $\mathbf{O h} \boldsymbol{e t} \boldsymbol{a l}$. ${ }^{(6)}$ who reported that unilateral hydroceles dominated in the two groups and 
a nonsignificant change was found among groups regarding laterality $(\mathrm{p}$-value $=0.305)$. In contrast to our findings, Agnihotri et al. ${ }^{(7)}$ revealed that pain, and hematoma were more commonly detected in cases of group-II and the change in incidence of complications between both groups was significant.

In our results, we found that a highly significant change was found between both groups as regards surgical period. This result is in harmony with the result of Alp et al. (2) who showed that surgical period was significantly shorter in the scrotal-group. Agnihotri et al. ${ }^{(7)}$ showed that all processes were effectively finished without intra-operative complications connected to operation or to anesthesia in the two groups. There weren't complications connected to intra-operative aspirations of hydrocele fluids in the inguinal-group, and all the hydrocele sacs have been delivered simply into the inguinal wounds after aspirations. No primary reason for hydrocele has been reported in any case in the studied groups. Analogous findings have been concluded by $\mathrm{Oh}$ et $\boldsymbol{a l}$. (6) who illustrated that the surgical period was $30.94 \pm 3.95$-min in group-I and $38.02 \pm 7.12$-min in group-II. The operation time was shorter significantly in group-I as compared with groupII (p-value $<0.001$ ). The results of Agnihotri et al. ${ }^{(7)}$ are in agreement with our results as they mentioned that the mean surgical period was $45.90 \pm 10.67-\mathrm{min}$ in the inguinal-group and $38.10 \pm 10.44$-min in the scrotalgroup, which was significantly shorter in the scrotal group.

In the present study, we found that there was highly statistically significant change between both groups regarding post-operative hospitalization being shorter in the scrotal group. A significant change was found between both groups regarding overall satisfaction, while there was insignificant change among groups regarding early postoperative complications. Our findings are matching with Alp et al. (2) who revealed that the commonest early complications of scrotal hydrocelectomy was scrotal edema/induration, but a non-significant change was found in the entire number of early complications among the inguinal-groups and scrotal-groups $(\mathrm{p}=$ 0.416). As for hydrocele recurrences or testicular atrophy (delayed complications), they did not occur in the two groups. The total rate of success was $100 \%$ at the 6-mth follow-up after inguinal as well as scrotal hydrocelectomy. The scrotal scar was nearly invisible after 4-wks post-operatively. In contrast with our findings, Agnihotri et al. ${ }^{(7)}$ revealed that the mean extent of postoperative hospitalization was $4.24 \pm 1.64-$ days in the inguinal-group and $5.88 \pm 1.84$-day in the scrotal-group. The change in the mean interval of hospitalization among the studied groups was significant. In agreement with our findings, Oh et al. ${ }^{(6)}$ showed that the hospitalization was $3.94 \pm 0.30$-days in group I and $4.24 \pm 0.99$-days in group-II. The Hospitalization was shorter significantly in group-I (scrotal) as compared to group-II ( $\mathrm{p}$-value $=0.009$ ).
Agnihotri et al. (7) counted the minor to moderate scrotal tumefaction as an ordinary or agreeable sequela afterward hydrocelectomies, but the permanent long-standing edema is counted to be of the post-operative complications. The commonest postoperative complications met in cases of scrotalgroup were pains $(26 \%)$, permanent scrotal edema $(14 \%)$, hematoma $(10 \%)$ and fever $(8 \%)$. In the other hand, Agnihotri et al. ${ }^{(7)}$ reported that pain was found in only $6 \%$ and fever in only $4 \%$ of the cases of inguinalgroup whereas no one of the cases in this group revealed to have permanent scrotal edemas or hematomas. Additional complications detected in scrotal-group whereas not found in inguinal-group were wounds sepsis $(2 \%)$, wounds dehiscence $(2 \%)$ and seromas formations $(6 \%)$.

In the past 20-yrs Bassel et al. ${ }^{(8)}$ showed that scrotal method was utilized to manage the un-descended testis, it was declared that the related PPV can be ligated high sufficient. Although Wilson et al. ${ }^{(9)}$ found that the classic inguinal method is suggested for treating the communicating hydrocele. There is single report by Gökçora et al. (9) that matches inguinal hydrocelectomies and scrotal hydrocelectomies. Through spermatic cord rear grip throughout scrotal method, we can ligate the highest PPV with no harmful effect to the inguinal canal integrities. In this series, no change was observed regarding complications and rate of recurrence among scrotal \& inguinal methods. Gökçora et $\boldsymbol{a l}$. ${ }^{(9)}$ reported extra noticeable benefit of the scrotal method, which is the outstanding cosmesis. Fearne et al. (11) showed that in majority of cases, the scar is closely invisible. Koyle et al. (12) noticed additional benefit of the scrotal method, in that it permits reaching the scrotal fillings and elimination of the distal part of tunica vaginalis. Examination of the scrotal fillings decreases the risk of following noncommunicating hydroceles, and as well eliminates the risk of probable acute scrotal hematomas and permits the excisions of vestigial additions. By means of scrotal incisions in the scrotal skin folds leading to quicker surgical periods, reduced pains, and enhanced cosmesis in our cases. As we know, there are 3 practically dissimilar scrotal places to incise the scrotum: the scrotal inguinal crinkle, mid-line scrotal, and crosswise to rugae of scrotums. A mid-line scrotal incisions can enhance the cosmetic outcomes, particularly in twosided patients.

Lau et al. (13) showed that the laparoscopy method is additional way for treating the herniation and hydrocele in kids. It permits examination and mending of the herniation in the two groins. However, a new metanalysis on pediatric inguinal herniation by Yang et al. (14) concluded that the laparoscopy method is accompanied with a tendency to an elevated rate of recurrence and extended surgical period for unilateral maintenances, but faster surgical period for two-sided maintenances. Laparoscopically hydrocelectomies in the pediatric ages' group was concluded by Ho et al. ${ }^{(15)}$. However, the laparoscopy operational period was 
extended than that of scrotal hydrocelectomies, and the incisions scars perhaps were more obvious than the scrotal incisions scars. Furthermore, the costs was elevated in comparison with that of the scrotal method.

\section{CONCLUSION}

The scrotal method for treating the children communicated hydrocele can be another procedure in qualified centers. The key benefits of this method are cosmesis and reduced surgical period. But the commonest early complication is temporal scrotal edema. The major benefits of this method are cosmesis and reduced surgical period. However, the commonest early complication is temporal scrotal edema. This procedure delivers a simple method to the anatomical structure included in scrotal and groin pathologic characteristics with no disruptions of the inguinal duct integrity. The necessity for wounds edge retractions are lesser, and consequently lesser shocks are cautilized to the inguinal area.

\section{Financial support and sponsorship: Nil.}

\section{Conflict of Interest: Nil.}

\section{REFERENCES}

1. Soualili Z, Achouri D, Haif A et al. (2015): The interscrotal approach to inguinoscrotal pathologies. Arab J Urol., 13: 176-182.

2. Alp B, Irkilata H, Kibar Y et al. (2014): Comparison of the inguinal and scrotal approaches for the treatment of communicating hydrocele in children. The Kaohsiung Journal of Medical Sciences, 30 (4): 200-205.

3. Feng S, Yang H, Li X et al. (2016): Single scrotal incision orchiopexy versus the inguinal approach in children with palpable un-descended testis: a systematic review and meta-analysis. Pediatric Surgery International, 32 (10): 989-995.

4. Ramachandran $\mathrm{K}, \quad$ Vigneshwar $\quad$, Lakshminarayanan $\mathrm{P}$ et al. (2021): A comparative study between inguinal approach of hydrocele and scrotal approach of hydrocele", 2021. International Journal of Current Research, 13 (5): 17228-17230.
5. Lee S, Park P (2020): Incidence of Cord Hydrocele After Laparoscopic Intracorporeal Inguinal Herniation Repair in Male Pediatric Patients: A Comparative Study Between Removing and Leaving the Herniationl Sac. Journal of Laparoendoscopic \& Advanced Surgical Techniques, 30 (5): 596-602.

6. Oh J, Chung H, Yu H et al. (2018): Hydrocelectomy via scrotal incision is a valuable alternative to the traditional inguinal approach for hydrocele treatment in boys. Investigative and Clinical Urology, 59 (6): 416421.

7. Agnihotri I, Jain S, Swarnkar M (2018): Comparative study of inguinal versus scrotal approach in idiopathic vaginal hydrocele. International Surgery Journal, 5 (4): 1464-1468.

8. Bassel Y, Scherz H, Kirsch A (2007): Scrotal incision orchiopexy for un-descended testes with or without a patent processus vaginalis. The Journal of Urology, 177 (4): 1516-1518.

9. Wilson J, Aaronson D, Schrader R et al. (2008): Hydrocele in the pediatric patient: inguinal or scrotal approach?. The Journal of Urology, 180 (4): 1724-1728.

10. Gökçora I, Yagmurlu A (2003): A longitudinal followup using the high trans-scrotal approach for inguinal and scrotal abnormalities in boys. Herniation, 7 (4): 181-184.

11. Fearne C, Abela M, Aquilina D (2002): Scrotal approach for inguinal herniation and hydrocele repair in boys. European Journal of Pediatric Surgery, 12 (02): 116-117.

12. Koyle M, Walsh R, Caruso A et al. (1999): Scrotal (Bianchi) approach to patent processus vaginalis in children. Techniques in Urology, 5 (2): 95-99.

13. Lau S, Lee Y, Caty $M$ (2007): Current management of herniations and hydroceles. In Seminars in Pediatric Surgery, 16 (1): 50-57.

14. Yang C, Zhang $\mathrm{H}$, Pu J et al. (2011): Laparoscopic vs open herniorrhaphy in the management of pediatric inguinal herniation: a systemic review and metaanalysis. Journal of Pediatric Surgery, 46 (9): 18241834.

15. Ho C, Shei-Dei Y, Tsai Y (2010): Minilaparoscopic high-ligation with the processus vaginalis undissected and left in situ is a safe, effective, and durable treatment for pediatric hydrocele. Urology, 76 (1), 134-137. 